\title{
A Case Report on Churg Strauss Syndrome
}

\author{
Danisha P1, Rohini SP2,", Sayed Mohammed Samsudeen² \\ ${ }^{1}$ Department of Pharmacy Practice, Al Shifa College of Pharmacy Perinthalmanna, Kerala University of Health Sciences, Malappuram, \\ Kerala, INDIA. \\ ${ }^{2} \mathrm{Al}$ Shifa College of Pharmacy Perinthalmanna, Kerala University of Health Sciences, Malappuram, Kerala, INDIA.
}

\begin{abstract}
Churg-Strauss syndrome (CSS) is a rare disorder that affects medium to small sized vessels, multiple organ systems especially the lungs. The disorder is characterized by hypereosinophilia in the blood and tissues, inflammation of blood vessels (vasculitis) and the development of inflammatory nodular lesions called granulomas (granulomatosis). This report refers to a 72 year old female patient presented with sudden and abrupt onset of asthma and breathlessness with other complaints of peripheral neuropathy and generalised weakness. Laboratory investigation showed her to be hypereosinophilic, positive p-ANCA (perinuclear Anti-Neutrophil Cytoplasmic Antibodies) and nerve biopsy revealed vasculitis. We report a case on Churg Strauss Syndrome with hypereosinophila, vasculitis and asthma, effectively treated with corticosteroid and immunosuppressant.
\end{abstract}

Key words: Churg Strauss Syndrome, Asthma, p-ANCA, Vasculitis, Granulomatosis, Hypereosinophilia, Corticosteroids, Immunosuppressant.

\section{INTRODUCTION}

Churg Strauss Syndrome (CSS) or Allergic Angitis and Granulomatosis is an idiopathic multisystem vasculitis of small and mediumsized arteries that occurs in patients with asthma. ${ }^{1}$ CSS is often refered to as a quite rare, non-communicable systemic disease and not inherited, that often occurs in people with a previous incidence of bronchial asthma. Ironically the etiology of Churg Strauss Syndromeis still unknown, though it's always accounted for hypersensitivity to an inhaled agent and asthma remains one of the main differentiating characteristic of this syndrome..$^{2-6}$ It is very uncommon to associate CSS with any parasitic infection or antigenic drug as a triggering event. The hallmarks of CSS are Peripheral eosinophilia, necrotizing vasculitis and multiple organs involvement. ${ }^{1}$ The main organs involved are first lungs and then, followed by kidneys. Throwing light upon the differential diagnosis of Churg Strauss Syndrome, it is confirmed if four or more of the following medical signs exist at the time of investigation asthma, greater than $10 \%$ eosinophilia, mono or poly neuropathy which is rationalized for systemic vasculitis, pulmonary opacities, abnormalities of sinus cavity and extra vasculareosinophils. The histopathological analysis clearly reveals necrotizing vasculitis and inflammatory infiltrate with high eosniophills with necrotizing granulomas.

\section{CASE REPORT}

A 72 year old female patient was presented with complaints of cough and breathlessness which severed on lying since 4 days, peripheral neuropathy and generalized weakness since 4 days. She had fever and difficulty to walk without a support. She had a history of old Cerebro Vascular Accident (CVA), Chronic Kidney Disease (CKD) and Steroid induced hyperglycaemia.

Her general examination showed a pulse rate of $108 / \mathrm{min}$, respiratory rate $28 /$ min and blood pressure was $120 / 80 \mathrm{~mm}$ of $\mathrm{Hg}$. Respiratory system examination revealed bilateral expiratory ronchi and crept.
DOI: 10.5530/ijopp.12.1.15

Address for correspondence: ROHINI S.P,

Pharm.D Intern, Al Shifa College of Pharmacy Perinthalmanna, Kerala Univeristy of Health Sciences, Malappuram, Kerala INDIA.

Phone no: +91 9447989434 Email Id: rohiniprasannan@ gmail.com

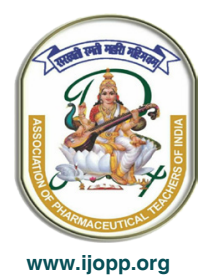


Contrast enhanced computed tomography of thorax revealed right bilateral lower lobe greater than medial segment of middle lobe and posterior segment of upper lobe. Nerve biopsy showed possible vasculitis. Laboratory Investigation revealed haemoglobin $10.2 \mathrm{mg} / \mathrm{dl}$, total leukocyte count 30*1000 cells/cumm, neutrophil-64\%, lymphocyte- $18 \%$, monocytes- $4 \%$, eosinophils- $20 \%$, platelet count $-489 * 1000$ cells / cumm, ESR-95mm/ $\mathrm{hr}$ and $\operatorname{IgE}$ was $88.6 \mathrm{mcg} / \mathrm{ml}$ and a positive p-ANCA (perinuclear Anti-Neutrophil Cytoplasmic Antibodies). Broncho Alveolar Lavage was performed, the sample revealed no fungal element and granuloma. The patient had a negative Acid-Fast Bacteria and had a gram stain with a presence of inflammatory cells. Blood urea and creatinine were elevated with a B Natriuretic Peptide (BNP) value of $229 \mathrm{pg} / \mathrm{ml}$, CRP value $65.82 \mathrm{UL}$ and serum procalcitonin $0.07 \mathrm{ng} / \mathrm{ml}$.

She was treated with Injection Hydrocortisone $100 \mathrm{mg}$ 3 times for 3 days followed with oral Prednisolone $30 \mathrm{mg}$ once daily followed with $10 \mathrm{mg}$ twice daily. Tablet Mycophenolate Mofetil $500 \mathrm{mg}$ twice was given for first three days followed with $1000 \mathrm{mg}$ once daily for two days. Given Aminophylline 1 ampoule in $250 \mathrm{ml}$ NS 10 drops/minutes on administration. Bilevel Positive Airway Pressure (BPAP) was indicated but reverted back to mask since was not being tolerated.

\section{DISCUSSION}

The diagnosis of CSS is a clinical one and is often alleged when a healthy individual is impersonated with a sudden adult onset of allergic rhinitis and asthma followed with systemic vasulitis. The major problem associated with the diagnosis is both asthma and rhinitis are very common in individuals and these symptoms herald the beginning of vasulitis by many years with a mean latency of ${ }^{7}$ years. ${ }^{8,7}$ here are different categories of diagnostic criteria for CSS initially proposed by Churg and Strauss in 1951, followed by Lanham and colleagues in 1984, American College of Rheumatology in 1990 and Chapel HIII Consensus Conference in 1994. ${ }^{\circ}$ All of these criteria were criticised by a special workshop of the US National Institute of Health which elucidated some difficulties in their application; claiming that CSS arises in individuals who don't have any features of Peripheral Eosniphilia.

Our patient satisfied the diagnostic criteria with asthma, peripheral vasculitis involving peripheral nerves and eosinophilia with a positive PANCA test supported with nerve biopsy. This 75 year old patient has a history of cerebrovascular accident. A history of asthma precedes the appearance of syndrome and in our case; asthma was present years before the CSS. For patients with vasculitis, the presence of asthma and eosnophilia was $90 \%$ sensitive and $99 \%$ specific. Pulmonary involvement is nearly universal in CSS. Most patients have asthma initially whose severity increases over time and resolves with the onset of vasculitis. Computed Tomography of sinus and chest can confirm the presence of sinusitis and pulmonary infiltrates. Cardiac or GI involvement and age 65 years are indicated with worse prognosis. Blood Urea and Creatinine are mildly elevated suggesting renal involvement. Elevated cardiac bio-marker BNP $(229 \mathrm{pg} / \mathrm{ml})$ suggests hemodynamic stress.

Corticosteroids are the first line therapy for CSS. Involvement of other organ system in a chronic case necessitates the addition of other immunosuppressant to the therapy. Antineutrophil cytoplasmic antibodies, although a marker of disease, may not reliably correspond with disease activity and hence might not be valuable in assessment of disease remission in all patients. ${ }^{9}$ Our patient was considered to have a chronic phase and thus treated with corticosteroids and immunosuppressant. Initially IV corticosteroids were administered and changed to the oral route and further the dose was tapered. IV corticosteroid, followed with oral dosage and tapering of dose. Immunosuppressant Mycophenolate was given and other co-morbid conditions were treated with specifically indicated drugs. Corticosteroid and immunosuppressant especially Mycophenolate considerably improved the prognosis and overall survival rate in patients with vasculitis.

\section{CONCLUSION}

Clinical diagnosis of CSS is difficult as the symptoms of the disease overlaps with usual symptoms of severe asthma. Nevertheless asthamtic presentation in adults associated with gastrointestinal signs, renal or cardiac abnormality and pulmonary infiltrates resembling allergic alveolitis should be suspected for plausible emergence of CSS. The unwavering association of CSS with asthma alone stands as the major differentiating factor of CSS from other vasculitides. With the introduction of corticosteroid therapy the remission and survival rates have improved. Patients with limited organ involvement improve with the administration of immunosuppressant. Even after completion of the therapy the CSS patients stipulate a continuous observation.

\section{ACKNOWLEDGEMENT}

The authors are thankful to the management of KIMS ALSHIFA hospital, Department of General Medicine 
and Department of Pharmacy Practice, AL SHIFA COLLEGE OF PHARMACY for supporting the work.

\section{CONFLICT OF INTEREST}

The authors declare no conflict of interest.

\section{ABBREVIATIONS}

CSS: Churg Strauss Syndrome; CVA: Cerebro Vascular Accident; CKD: Chronic Kidney Disease; p-ANCA: Perinuclear Anti-Neutrophil Cytoplasmic Antibodies; BNP: B Natriuretic Peptide; BPAP: Bilevel Positive Airway Pressure.

\section{SUMMARY}

CSS is a systemic vasculitis consisting of asthma, eosinophilia and fever and accompanying vasculitis of various organ systems. Asthma is one of the cardinal features of CSS, typically affecting individuals with a history of new-onset or newly-worsened asthma. The cause of CSS is unknown but certainly is multi-factorial but lacks definitive evidence. CSS usually responds to steroids and immune suppressants. The course and length of the treatment will depend upon the severity of the disease and the organs involved.

\section{REFERENCES}

1. Churg J, Strauss L. Allergic granulomatosis, allergic angitis and periarteritis nodosa. Am J Pathol. 1951;27(2):277-301.

2. Frazier AA, De-Christenson RML, Galvin JR, Fleming MV. Pulmonary angiitis and granulomatosis: radiologic-pathologic correlation. Radiographics. 1998;18(3):687-710.

3. Mayberry JP, Primack SL, Müller NL. Thoracic manifestations of systemic autoimune diseases: radiographic and high-resolution CT findings. Radiographics. 2000;20(6):1623-35.

4. Johkoh T, Müller NL, Akira M, Ichikado K, Suga M, Ando M, et al. Eosinophilic lung diseases: diagnostic accuracy of thin-section in 111 patients. Radiology. 2000;216(3):773-80.

5. Castañer E, Alguersuari A, Gallardo X, Andreu M, Pallardó Y, Mata JM, et al. When to suspect pulmonary vasculitis: radiologic and clinical clues. Radiographics. 2010;30(1):33-53.

6. Chung MP, Yi CA, Lee HY, Han J, Lee KS. Imaging of pulmonary vasculitis. Radiology. 2010;255(2):322-41.

7. Chumbley LC, Harrison EG, De Remee RA. Allergic granulomatosis and angiitis (Churg-Strauss syndrome). Mayo Clin Proc. 1977;52(8):477-84.

8. Guillevin L, Cohen P, Gayraud M, Lhote F, Jarrousse B, Casassus P. ChurgStrauss syndrome: clinical study and long-term follow-up of 96 patients. Medicine. 1999;78(1):26-37.

9. Imre N, Mary ES, Alan RL. Churg-Strauss syndrome. The Lancet. 2003;361(9357):588-94. 